\title{
Field Investigations on the Effects of Track Lateral Supports on the Ballasted Railway Lateral Resistance
}

\author{
Jabbar Ali Zakeri ${ }^{\star 1}$, Milad Alizadeh Galdiani², Seyed Ali Mosayebi² \\ 1 The Center of Excellence for Railway Transportation, School of Railway Engineering, Iran University of Science and Technology, \\ Tehran, 16844, Islamic Republic of Iran \\ 2 Department of Railway Track \& Structures Engineering, School of Railway Engineering, Iran University of Science and \\ Technology, Tehran, 16844, Islamic Republic of Iran \\ * Corresponding author, e-mail: zakeri@iust.ac.ir
}

Received: 16 December 2019, Accepted: 05 April 2020, Published online: 06 May 2020

\begin{abstract}
Lateral movements of the ballasted railway track especially in the continuous welded rail (CWR) occur in sharp curves because of high lateral forces. Several strategies have been proposed to increase the track lateral resistance which most of them related to track curves with small radii. In this paper, track lateral supports as a new method have been utilized and a series of field tests have been conducted by using the Single Tie Push Tests (STPT) and Multi Tie Push Tests (MTPT) and their results are compared with the numerical modeling. The results of numerical modeling and field tests show that the track lateral resistance significantly increases in the railway with lateral supports, so that the lateral displacements of track are as a bilinear form.
\end{abstract}

Keywords

ballasted railway track, lateral resistance, lateral supports, field and numerical studies

\section{Introduction}

Because of passing trains on railroads, different lateral and vertical forces are acted to railway tracks. The major effects of these forces are instability of wagons and lateral movements on the railroads. Lateral forces are perpendicular to main axis of rail which they are caused by two main factors; the first one is the lateral component of frictional force between wheel and rail (when train passes through curves, the frictional force is divided into two component that are parallel and perpendicular to main axis that the second component is considered as lateral force), the second one is due to contact between wheel and rail especially in the curves and rail buckling which is caused by axial loads due to changing rail temperature. Lateral displacement of railroad is longitudinal deviation of track which is caused by lateral forces and it may occur locally or widely along of the railroads. The lateral resistance is the most important factor in order to prevent railway buckling and lateral displacements by providing stability and limited lateral displacements. Also, the lateral displacement of tracks depends on the lateral stiffness in curves [1]. There are many items that affect on the lateral resistance such as sleeper types, the space between sleepers and the quality of ballast between them. Based on the existing technical literature, interaction between ballast and sleepers is the main source of lateral resistance which is due to resistance in three areas including interaction between bottom surface of sleeper and ballast, interaction between the sides of sleeper and ballast and shoulder ballast [2,3]. The lateral resistance due to the interaction between sleeper and ballast depends on areas of bottom, sides and end of sleeper. When trains pass through railroad, vertical forces act to track and then they affect on frictional forces [4]. The passive force of ballast is the main reason for shoulder resistant at the sleeper end. As the passive forces mobilized in the ballast shoulder, increasing of them more than the specific amount do not cause to increase the lateral resistance [5]. Also, the mechanical characterization of the ballast such as ballast density and oedometric modulus affect on the ballast lateral resistance [6]. Xitrack was other technique which was based on polymeric materials. In this method, polymeric material was added to the ballast which resulted in raising the integration between ballast of railroad track and consequently lateral resistance increased noticeably [7]. Utilizing the frictional sleeper was an effective solution to improve 
the lateral resistance. In this method, some jags were created on the bottom surface of sleeper which increased frictional interaction between bottom of sleeper and ballast and consequently the frictional coefficient increased by $67 \%$ [8] The nailed sleeper was a method whose result showed that using a pair of nails of $40 \mathrm{~mm}$ in diameter and $1500 \mathrm{~mm}$ in length could increase the lateral resistance more than twice compared to the normal condition [9]. Geogrid-reinforced ballast was a method that improved the lateral resistance. In this method, some layers of geogrid were installed among ballast layers which improved performance of ballast and track lateral resistance [10, 11]. Utilizing frame-shaped, Y-shaped, and dual-block ties can also lead to increase in track lateral resistance because of their specific geometry [12]. By using Y-shape sleepers, the lateral resistance increases in continuously welded rail track specially in curves $[13,14]$. According to the previous research, shoulder ballast geometry dimensions affected on the lateral resistance and the value of mobilized resistance at the end of sleeper depended on the ballast shoulder dimension [15]. Based on another investigation on the lateral resistance, side ballast, shoulder ballast and the interaction between ballast and bottom surface of sleepers provided the lateral resistance by proportions of 37-50\%, $15-37 \%$ and $26-35 \%$, respectively. Also based on results of tests conducted on the lateral railway resistance, portion of the ballast, rail and fastening system on the lateral resistance were respectively $65 \%, 25 \%$ and $10 \%$ resistance respectively [15]. According to the previous investigations by using one, two and three stiffeners under the steel sleepers, the lateral resistance increased $24 \%, 140 \%, 203 \%$ respectively in the comparison with a regular steel sleeper in ballasted track [16].

In another investigation, the relationship between the lateral resistance and vertical loads had been studied so that by increasing the vertical loads, the lateral resistance increased [17]. The best solution to prevent the lateral sleeper displacement is increasing the track lateral stiffness. This research presents lateral supports as a new method for increasing the lateral resistance which is like small piles to improve the lateral resistance significantly. For this reason, in this research first the numerical model of railway track for measuring the effects of lateral supports is presented. Then, a series of field tests for investigating the installed lateral supports in track are done. In field investigations, the Single Tie Push (STPT) and Multi Tie Push (MTPT) tests are done to measure the improving the track lateral resistance by lateral supports.

\section{Numerical model of track}

In the current study, the track was modeled for two cases, the first case was a model without lateral supports and the second case was a ballasted track with lateral supports. The properties of track modeling were same as the track which a series of field tests were done on it. The location of the test was in $\mathrm{km} 141 \mathrm{~km}+291 \mathrm{~m}$ of the northern region of Iranian railway track between Bonekoh station and Kabutardare station. As the lateral displacement in the steep horizontal curves is critical, consequently a horizontal curve with radius $350 \mathrm{~m}$ was selected for this study. Other properties of the track were completely same as Iranian railway including shoulder width: $40 \mathrm{~cm}$, depth of ballast under sleeper: $30 \mathrm{~cm}$, rail profile: UIC60, and concrete sleeper type: B70. The railway track was modeled in the FE software (Abaqus) as shown in Fig. 1.

Since there are many factors affecting on the lateral resistance including interaction between parts of track such as sleeper, rail, ballast and pad, therefore for numerical modeling, the geometry of railway and properties of track lateral supports were considered exactly based on properties of track which was located in curve with 350 m radius.

According to the Iranian railway standard, mechanical properties of rail, sleeper and pad were introduced to the software based on presented data in Table 1. In this research, the railway track including rail, sleeper, ballast, and pad were modeled based on Abaqus finite element software. The ballasted track was simulated as a curve with $350 \mathrm{~m}$ radius and lenght of 45 meters long model. Static loadings with $120 \mathrm{kN}$ according to loading pattern in MTPT test were applied into railhead perpendicular

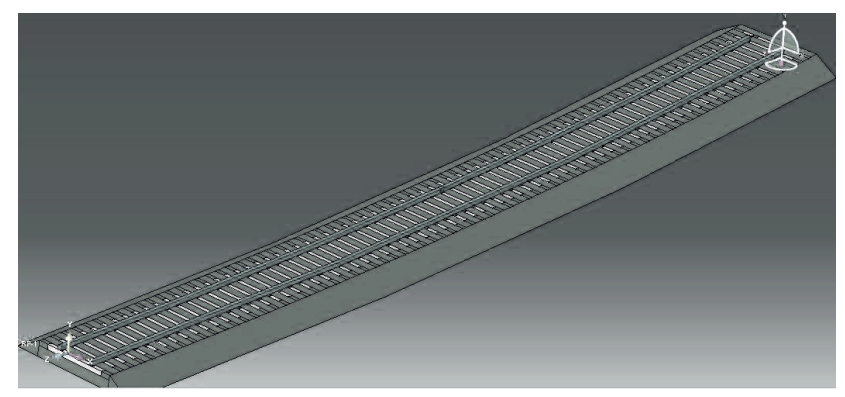

Fig. 1 Model of railway in finite element software

Table 1 Mechanical properties of materials

\begin{tabular}{lccc}
\hline & $\begin{array}{c}\text { Poisson } \\
\text { coefficient }\end{array}$ & $\begin{array}{c}\text { Young } \\
\text { Modulus (E) }\end{array}$ & $\begin{array}{c}\text { Weight per unit } \\
\text { volume }\end{array}$ \\
\hline Rail UIC60 & 0.3 & $210 \mathrm{GPa}$ & $60.34 \mathrm{~kg} / \mathrm{m}$ \\
Sleeper & 0.1 & $40 \mathrm{GPa}$ & $2600 \mathrm{~kg} / \mathrm{m}^{3}$ \\
Pad & 0.4 & $1 \mathrm{GPa}$ & $1800 \mathrm{~kg} / \mathrm{m}^{3}$ \\
\hline
\end{tabular}


to track axis toward outer side of curve. The interaction between sleeper and ballast was frictional by considering the frictional coefficient 0.8 . Since thickness of railway track component varied from $5 \mathrm{~mm}$ in rail pad to $50 \mathrm{~cm}$ in ballast layer, the meshing in the model have been done accurately for analyzing the lateral resistance of railway track precisely. Several studies were conducted to select the suitable profile for lateral supports. Finally, by considering many factors such as stiffness, flexural resistance and practical issue, U-Normal Profile (UNP180) was selected [18]. Therefore, their geometrical properties were considered based on Fig. 2.

Also, the steel type of track lateral supports was ST37 based on DIN 17100 standard, and their mechanical properties such as yield stress and ultimate stress were $235 \mathrm{MPa}$ and $370 \mathrm{MPa}$ respectively. Based on accomplished calculations and engineering judgment, shown in Fig. 3, one support was installed for each five sleepers. Length of the lateral supports and position of them are shown schematically in Fig. 4.

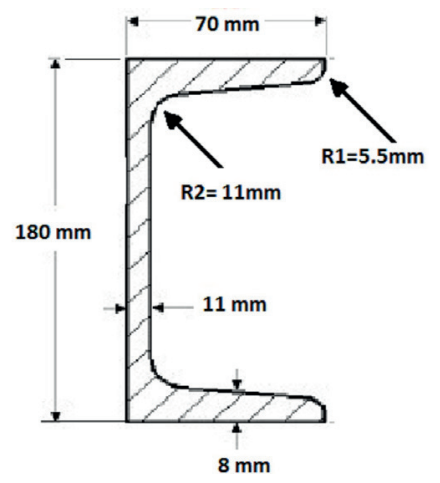

Fig. 2 Cross-section of track lateral support (UNP180)

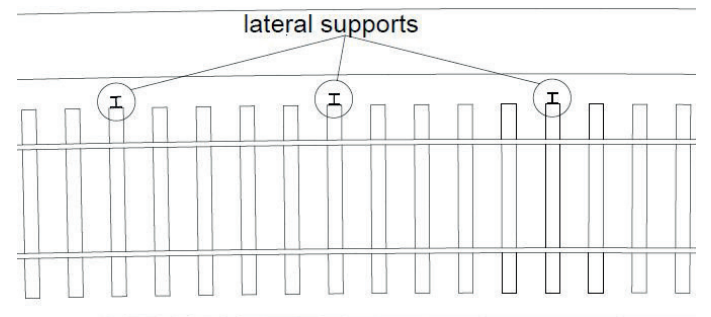

Fig. 3 Positions of track lateral supports

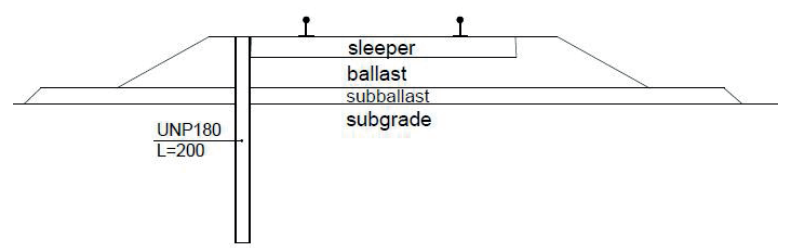

Fig. 4 Cross-section of railway track with lateral support
It should be noted that the relationship between lateral force and displacement were investigated for both tracks with and without lateral supports.

\section{Lateral supports in railway track}

Location of site for studying the ballasted track with lateral supports was selected according to following factors:

a. The site was considered in the railway track curve whose radius was less than 400 meters because of the most of buckling occurred in the steep curve.

b. The number of track buckling reported in the site should be noticeable and more than other curves, in other words, the track maintenance costs should be higher than other railway track curves because of many numbers of buckling.

Finally, by considering above factors, $\mathrm{km} 141 \mathrm{~km}+291 \mathrm{~m}$ in the northern region of Iranian railway track between Bonekoh and Kabutardare stations was selected for investigating a series of field tests. The properties of the track curve are shown based on Table 2 .

Before doing the tests, all rail joints were welded by Flash Butt Welding (FBW) Machine. By welding rails, the risk of buckling in CWR track increased due to rail longitudinal forces especially thermal forces. For installing the lateral supports in the track, firstly shoulder ballast was removed then lateral supports were installed in suitable places. In this process, distance and angle between profile and sleeper and angle between the profile and pneumatic hammer should be regulated carefully. Finally, by pneumatic hammer and air compressor, lateral supports were installed in track (Fig. 5).

Factors such as installing the lateral supports accurately at the most appropriate place, removing the shoulder ballast, around lateral support axis during installation (preventing from rotation of profile (support element)) were important for installing the lateral supports. One of the most important items to install the supports was the profile direction. In this regard, the profile should be placed in the proper direction, and also the profile should be perpendicular to track direction so that it caused a better

Table 2 Properties of the track curve between Kabutardare- Bonekoh stations

\begin{tabular}{lccc}
\hline Parameters & Values & Parameters & Values \\
\hline $\begin{array}{l}\text { Inner } \\
\text { kilometers }\end{array}$ & $141 \mathrm{~km}+291 \mathrm{~m}$ & $\begin{array}{c}\text { Track curve } \\
\text { radius }\end{array}$ & $350 \mathrm{~m}$ \\
$\begin{array}{l}\text { Outer } \\
\text { kilometers }\end{array}$ & $141 \mathrm{~km}+490 \mathrm{~m}$ & Total length & $165 \mathrm{~m}$ \\
Curve length & $45 \mathrm{~m}$ & & \\
\hline
\end{tabular}


performance for increasing the lateral resistance. Another important item was the distance between profile and sleeper. In this regard, for reducing the distance as minimum as possible, it was necessary to install lateral supports accurately. The angle of pneumatic compressor hammer used in this research was perpendicular to sleeper for installing the lateral supports. Thus, all lateral supports have been installed vertically (Fig. 6). According to lateral supports installed at the end of sleepers, railway track maintenance machines including tamping, and regulation could be applied without any restriction.
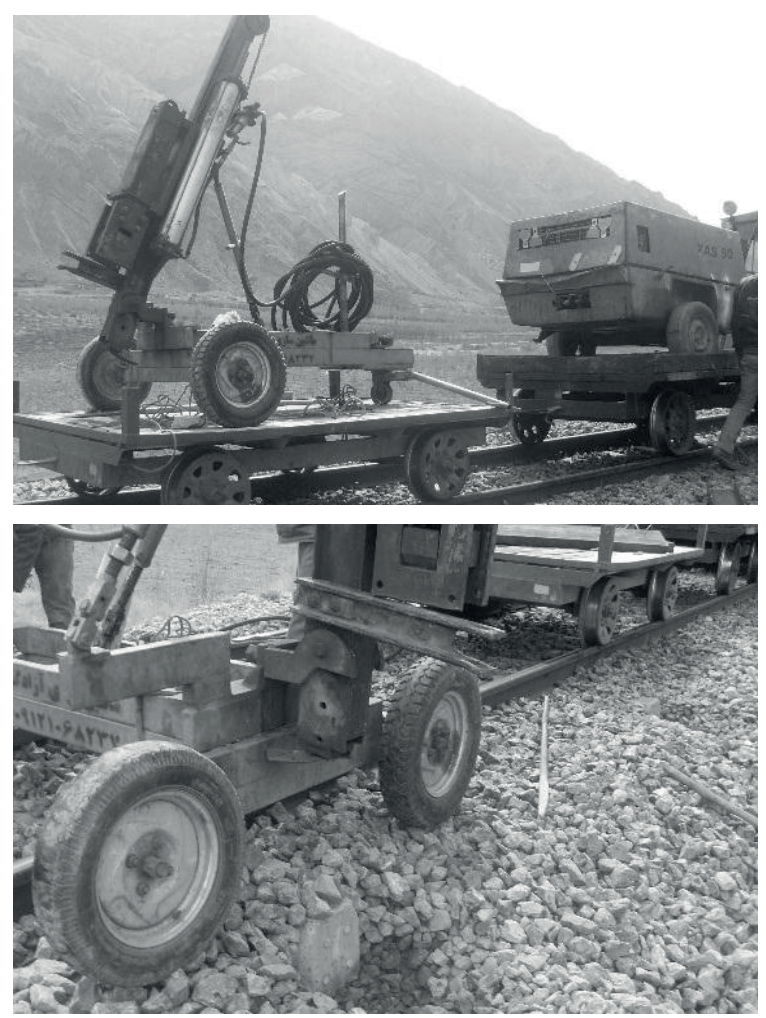

Fig. 5 Installing the lateral supports in ballasted track

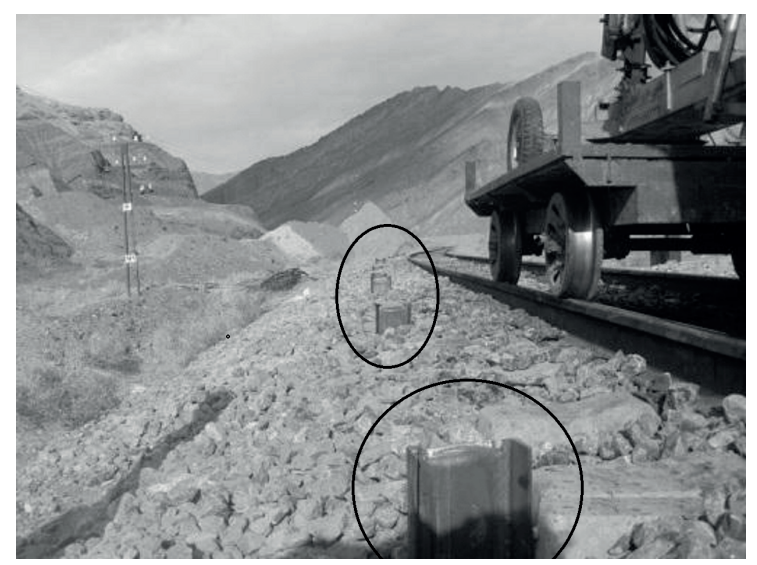

Fig. 6 Railway track with lateral supports

\section{Field tests}

For investigating the effects of lateral supports in ballasted track, Single Tie Push Test (STPT) and Multi Tie Push Test (MTPT) were utilized. In STPT, initially fastenings of a sleeper are opened and then the lateral force is applied to the sleeper by hydraulic jacks in the perpendicular direction to rail and sleeper displacement is measured by Linier Variable Displacement Transducer (LVDT) that is installed at the end of a sleeper. KS625N is a device including the processor, displacement gauge, hydraulic jack, electric pump, hydraulic oil tank and oil hoses to transfer pressure from the pump to the hydraulic cylinder [19]. Fig. 7 shows the device of STPT that records corresponding force against sleeper displacement each $0.5 \mathrm{~mm}$ up to $2 \mathrm{~mm}$.

The second test conducted in this research is Multi Tie Push Test (MTPT) that the process of that is applying the force to railway track so that the length of track test is 4 to 6 meters. The lateral force is applied to track by hydraulic jacks and in other side of track LVDTs are installed that record related displacements. Lateral force is applied to flange of rail which is read from the gauge connecting to jack. On the other side of track, 3 pieces of LVDTs by measuring displacements up to $15 \mathrm{~cm}$ are installed to sleepers that they are connected to the data processor device (Fig. 8). Finally, the force - displacement plot is drawn according to the $\mathrm{kN}-\mathrm{mm}$. The required equipment for MTPT tests are: Processor data device, Electric engine, Hydraulic jacks with a capacity of 30 tons, Wires to connect LVDT devices to computer, Support structure for hydraulic jack to load lateral force to rail, and Supports of LVDTs.

\section{Results and discussion}

In this section, the results of numerical model and field experiments are presented.

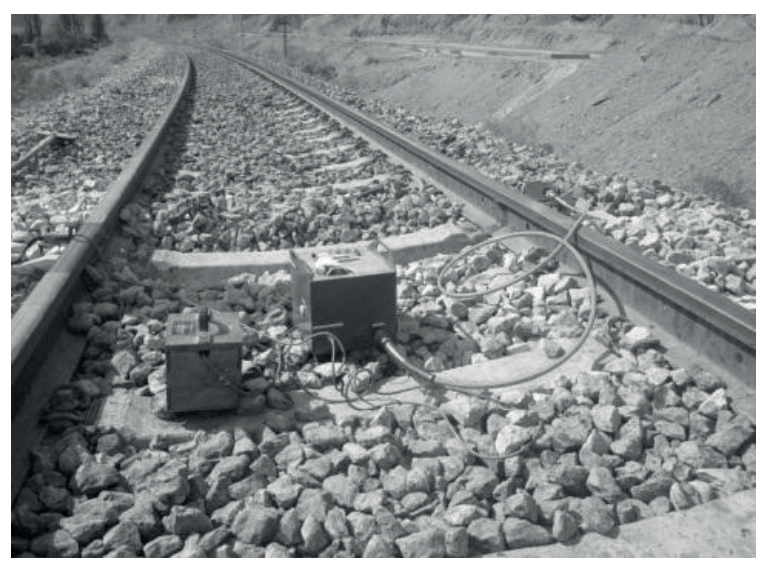

Fig. 7 Assembly of STPT 


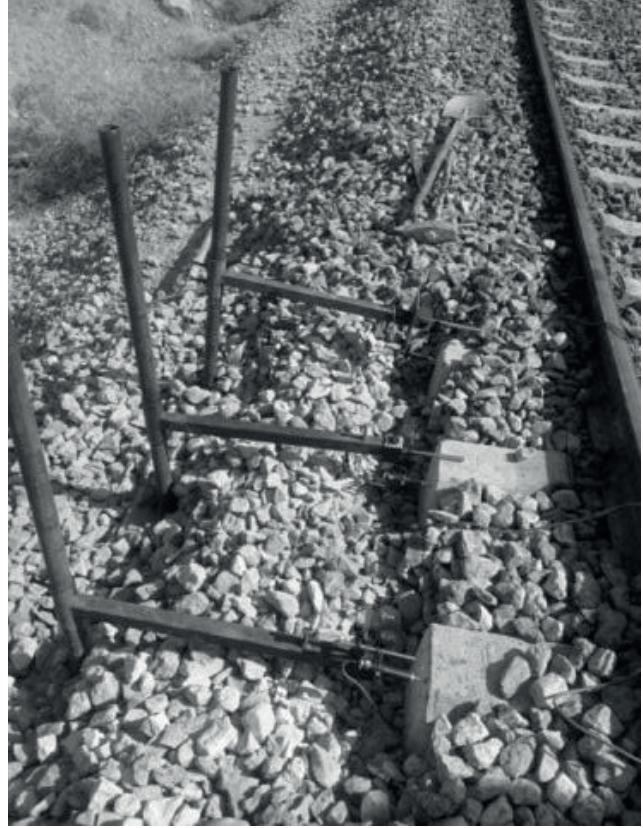

Fig. 8 LVDT supports

\subsection{Numerical results}

In this research, the railway track was modeled in a finite element software for two cases. One of them is railway track without lateral supports and second one is ballasted railway track with lateral supports. The results are presented in Fig. 9.

When lateral forces load to railway track without lateral supports, the force - lateral displacement diagram is approximately linear and by increasing lateral forces, lateral displacements increase; whereas in the railway track with lateral supports, the force-lateral displacement diagram is different so that by increasing the lateral forces, lateral displacements increase up to two millimeters, but after two millimeters due to the contact between lateral supports and sleepers, the track panel does not move more.

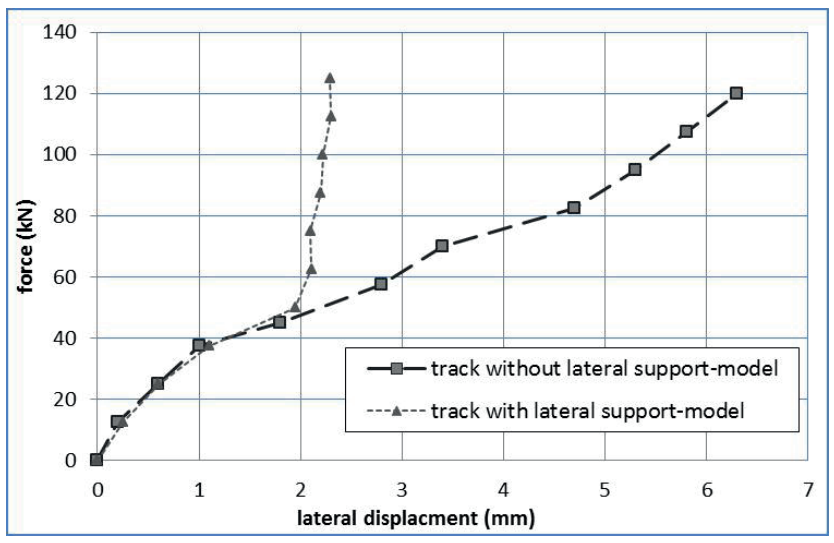

Fig. 9 Results of track model in FEM software

\subsection{Field test results}

Two categories of STPT were performed in this research, one of them in the ballasted railway track without lateral supports and another one the ballasted railway track with lateral supports. A series of field tests was done for these cases including STPTs on the ballasted railway track with and without lateral supports in the beginning of the track curve, in the center of the curve, and in the end of the track curve. Figs. 10, 11, and 12 indicate the results of STPT in the mentioned cases, respectively.

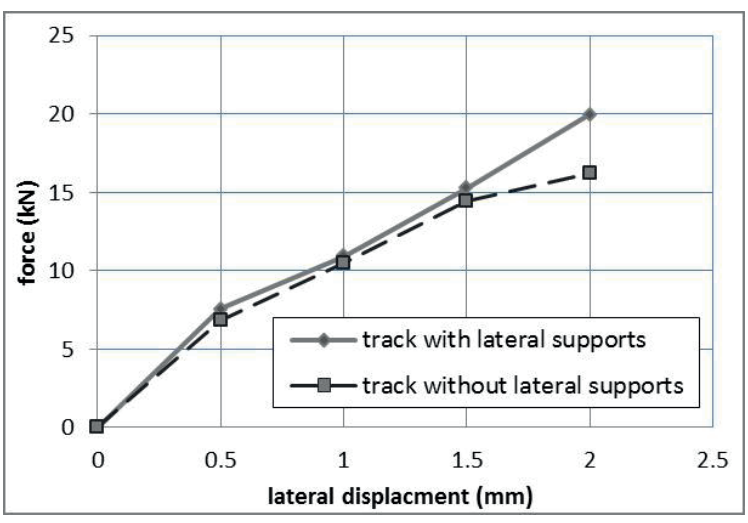

Fig. 10 STPTs in beginning of the track curve

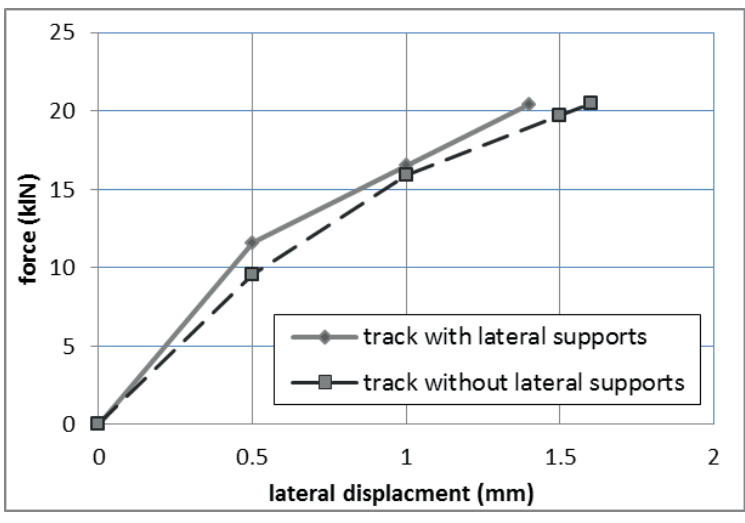

Fig. 11 STPTs in center of the track curve

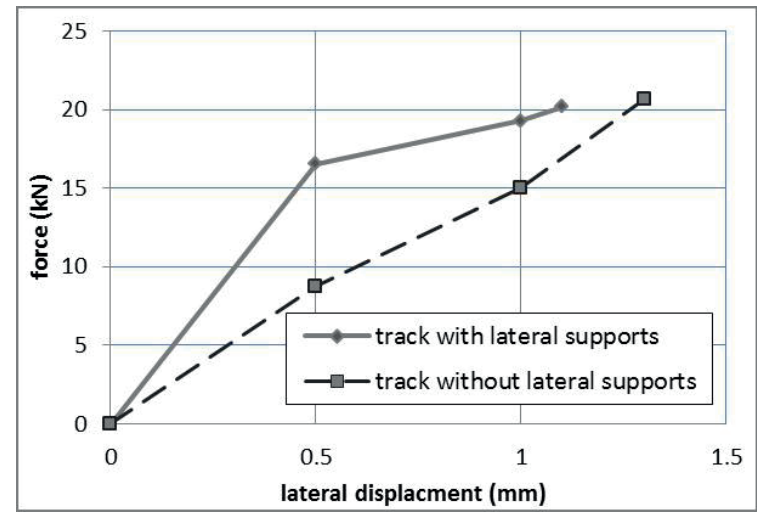

Fig. 12 STPTs in end of the track curve 
Since the capacity of jack is 2 tons and the maximum displacement that can be measured by LVDT is $2 \mathrm{~mm}$, load, and displacement axis in graphs of STPT are limited to $20 \mathrm{kN}$ and $2 \mathrm{~mm}$ respectively. Fig. 11 indicates that the lateral resistance increases by 23 percent and also results of Figs. 10 and 12 depict that the lateral resistance increases but because of the capacity of the jack and KS625N device, it is impossible to measure the increase of lateral resistance exactly. Because of this issue, MTPTs are utilized to measure the track lateral resistance.

MTPTs were done for two cases; the first case was for ballasted railway track without lateral supports and the second case for railway track with lateral supports. In these tests, the lateral force is applied by hydraulic jack, and the lateral displacement is measured by LVDTs and, consequently, the graphs according to force-displacement are achieved. Fig. 13 shows results of field experiments for two cases mentioned above.

The results of Fig. 13 indicate that up to $2 \mathrm{~mm}$ displacement, the diagram related to track with lateral supports is almost linear, but after $2 \mathrm{~mm}$ displacement, the move of sleepers stops completely. Consequently, the lateral resistance increases dramatically, and sleepers do not move more. Therefore, this graph has a bilinear form. For validating the results of numerical model, the results of MTPT tests and numerical models are presented in Figs. 14 and 15. These figures show that the results of numerical model and MTPT tests have good agreement.

\section{Conclusions}

The track lateral resistance is one of the most important factors in determining the technical performance and structural stability in railway engineering. Recently, many methods have been proposed for increasing the track

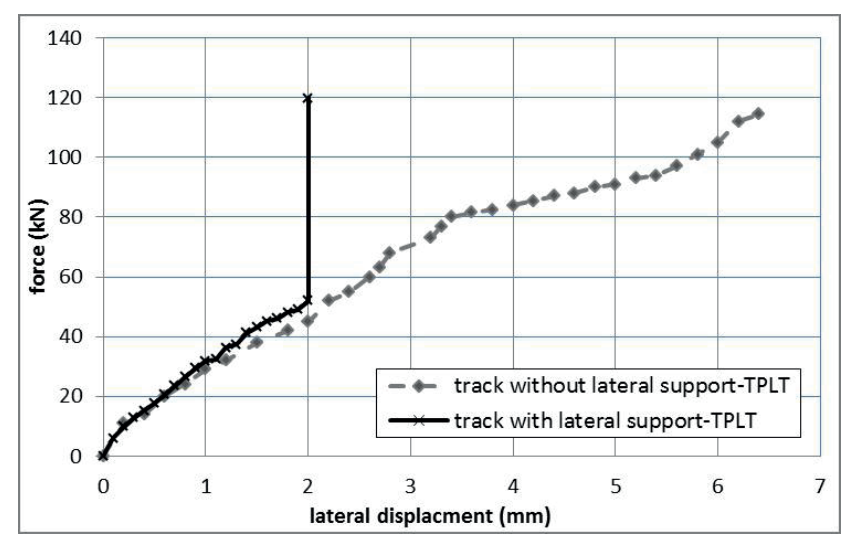

Fig. 13 Results of field experiments (MTPT)

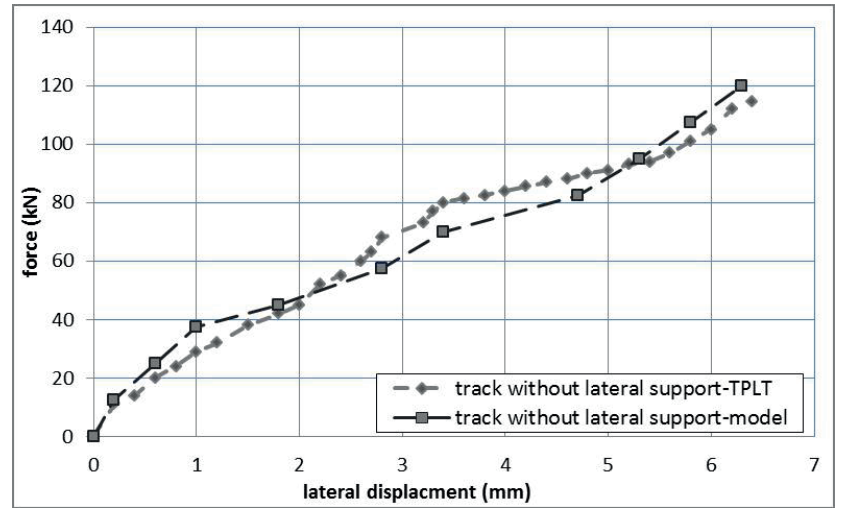

Fig. 14 Field and numerical results in the railway track without lateral supports

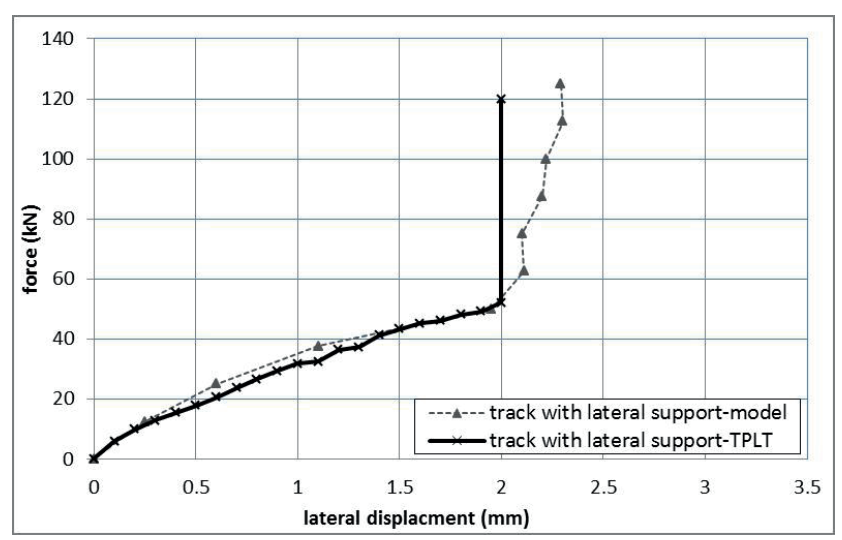

Fig. 15 Field and numerical results in the railway track with lateral supports

lateral resistance. This research presents a new method for providing the lateral resistance in the ballasted railway especially in track curves. For this purpose, lateral supports were introduced and installed in the railway curve and then numerical models and field tests were performed to evaluate the track lateral resistance. In this regard, STPTs and MTPTs and numerical models were done for two cases including ballasted track with and without lateral supports. Since STPTs couldn't measure displacement more than $2 \mathrm{~mm}$ and the capacity of the hydraulic jack was limited to $2000 \mathrm{~kg}$, it was impossible to evaluate the lateral resistance exactly. For this reason, MTPT tests were done to evaluate the performance of lateral supports. Results of MTPT tests indicated that the installation of lateral supports in the northern part of Iranian railway increased values of lateral resistance noticeably. In fact, it can be concluded that up to $2 \mathrm{~mm}$ displacement, the lateral force increased as a linear form, but when sleepers stuck to the lateral supports completely, the track lateral displacement stopped and panel did not move more 
while the applied forces increased. Therefore, the graph of force - displacement was as a bilinear form. Also, results of numerical models and MTPT tests have good agreement that this issue proved the good performance of lateral supports in ballasted tracks, especially in curves. This

\section{References}

[1] Zakeri, J. A., Mohammadzadeh, S., Barati, M. "New Definition of Neutral Temperature in Continuous Welded Railway Track Curves", Periodica Polytechnica Civil Engineering, 62(1), pp. 143-147, 2018. https://doi.org/10.3311/PPci.8505

[2] Zakeri, J. A. "Lateral Resistance of Railway Track", In: Perpinya, X. (ed.) Reliability and Safety in Railway, IntechOpen, Shanghai, China, 2012, pp. 357-374. https://doi.org/10.5772/35421

[3] Le Pen, L. M., Powrie, W. "Contribution of Base, Crib, and Shoulder Ballast to the Lateral Sliding Resistance of Railway Track: A Geotechnical Perspective", Proceedings of the Institution of Mechanical Engineers, Part F: Journal of Rail and Rapid Transit, 225(2), pp. 113-128, 2011.

https://doi.org/10.1177/0954409710397094

[4] Zakeri, J.-A., Mirfattahi, B., Fakhari, M. "Lateral resistance of railway track with frictional sleepers", Proceedings of the Institution of Civil Engineers - Transport, 165(2), pp. 151-155, 2012. https://doi.org/10.1680/tran.2012.165.2.151

[5] Kish, A. "On the Fundamentals of Track Lateral Resistance", presented at AREMA 2011Annual Conference, Minneapolis, MN, USA, Sept. 18-21, 2011. [online] Available at: https://www. arema.org/files/library/2011_Conference_Proceedings/On_the Fundamentals_of_Track_Lateral_Resistance.pdf

[6] Breul, P., Saussine, G. "On site mechanical characterization of the ballast state", Periodica Polytechnica Civil Engineering, 55(1), pp. 31-38, 2011.

https://oi.org/10.3311/pp.ci.2011-1.04

[7] Woodward, P. K., Kennedy, J., Medero, G. M., Banimahd, M. "Application of in situ polyurethane geocomposite beams to improve the passive shoulder resistance of railway track", Proceedings of the Institution of Mechanical Engineers, Part F: Journal of Rail and Rapid Transit, 226(3), pp. 294-304, 2011.

https://doi.org/10.1177/0954409711423460

[8] Zakeri, J. A., Esmaeili, M., Kasraei, A., Bakhtiary, A. "A numerical investigation on the lateral resistance of frictional sleepers in ballasted railway tracks", Proceedings of the Institution of Mechanical Engineers, Part F: Journal of Rail and Rapid Transit, 230(2), pp. 440-449, 2016.

https://doi.org/10.1177/0954409714543507

[9] Esmaeili, M., Khodaverdian, A., Neyestanaki, H. K., Nazari, S. "Investigating the effect of nailed sleepers on increasing the lateral resistance of ballasted track", Computers and Geotechnics, 71, pp. 1-11, 2016.

https://doi.org/10.1016/j.compgeo.2015.08.006 new method has many advantages such as: it is easy for implementing, no need to high costs, system performance is guaranteed, increasing the period of track maintenance, and no restrictions for maintenance and repair activities, such as the grinding, welding, and etc.

[10] Esmaeili, M., Zakeri, J. A., Babaei, M. "Laboratory and field investigation of the effect of geogrid-reinforced ballast on railway track lateral resistance", Geotextiles and Geomembranes, 45(2), pp. 23-33, 2017. https://doi.org/10.1016/j.geotexmem.2016.11.003

[11] Indraratna, B., Hussaini, S. K. K., Vinod, J. S. "The lateral displacement response of geogrid-reinforced ballast under cyclic loading", Geotextiles and Geomembranes, 39, pp. 20-29, 2013. https://doi.org/10.1016/j.geotexmem.2013.07.007

[12] Beck, A., Hempe, T., Schlender, T. "Experience Gained With Y-Steel Sleeper Track on German Rail (DB AG)", Rail Engineering International, 37(2), pp. 12-15, 2008.

[13] Liegner, N. "Investigation of the internal forces of the first track constructed with Y-shape steel sleepers under operation in Hungary summary of results of research", Periodica Polytechnica Civil Engineering, 48(1-2), pp. 115-130, 2004. [online] Available at: https://pp.bme.hu/ci/article/view/587

[14] Szabó, J. "Tests experiences in small radius curves of continuously welded rail tracks", Periodica Polytechnica Civil Engineering, 55(2), pp. 177-189, 2011.

https://doi.org/10.3311/pp.ci.2011-2.10

[15] Le Pen, L., Bhandari, A. R., Powrie, W. "Sleeper and Resistance of Ballasted Railway Tracks", Journal of Geotechnical and Geoenvironmental Engineering, 140(5), pp. 1-14, 2014. https://doi.org/10.1061/(ASCE)GT.1943-5606.0001088

[16] Zakeri, J.-A., Talebi, R. "Experimental investigation into the effect of steel sleeper vertical stiffeners on railway track lateral resistance", Proceedings of the Institution of Mechanical Engineers, Part F: Journal of Rail and Rapid Transit, 231(1), pp. 104-110, 2016. https://doi.org/10.1177/0954409715622500

[17] Zakeri, J. A., Barati, M. "Utilizing the track panel displacement method for estimating vertical load effects on the lateral resistance of continuously welded railway track", Proceedings of the Institution of Mechanical Engineers, Part F: Journal of Rail and Rapid Transit, 229(3), pp. 262-267, 2013.

https://doi.org/10.1177/0954409713508937

[18] Alizadeh Galdiani, M., Zakeri, J. A. "Feasibility of using lateral support in railway to increase lateral resistance in curves with small radius", In: 17th International Conference on Transport Engineering, Tehran, Iran, 2015.

[19] Zakeri, J. A., Bakhtiary, A. "Comparing lateral resistance to different types of sleeper in ballasted railway tracks", Scientia Iranica, 21(1), pp. 101-107, 2014. [online] Available at: http://scientiairanica. sharif.edu/article_1614.html 